Check for updates

Cite this: RSC Adv., 2017, 7, 47547

Received 20th July 2017

Accepted 25th September 2017

DOI: 10.1039/c7ra07992c

rsc.li/rsc-advances

\title{
Mercaptooxazole-phenazine based blue fluorescent sensor for the ultra-sensitive detection of mercury(II) ions in aqueous solution $\uparrow$
}

\author{
Hai-Li Zhang, Wen-Ting Li, Wen-Juan Qu, Tai-Bao Wei, (D) * Qi Lin, (D) * \\ You-Ming Zhang $\mathbb{D}^{*}$ and Hong Yao
}

\begin{abstract}
Herein, a mercury(॥) ion fluorescent sensor (Z-3) with high sensitivity and immediate response is designed and synthesized. The sensor uses the phenazine group as a luminophore and sulfhydryl as a recognition moiety. The sensor is easily synthesized and it exhibits a remarkable blue shift with $\mathrm{Hg}^{2+}$. Correspondingly, its fluorescence color changes from yellow to blue. In addition, the low naked eye detection limit $\left(10^{-5}\right)$ of the sensor allows the identification of concentration limits. Moreover, the sensor could detect mercury(॥) ions over a wide $\mathrm{pH}$ range (from 2 to 8), which indicates that the detection can be carried out in aqueous systems. In addition, test strips are fabricated, which could act as a convenient pathway for the recognition of $\mathrm{Hg}^{2+}$
\end{abstract}

\section{Introduction}

Mercury plays an important role in electrical and chemical applications. ${ }^{\mathbf{1 - 3}}$ Its electrical applications include thermometers, barometers, sphygmomanometers and other related instruments. In the chemical industry, mercury is used to electrolyze a salt for the preparation of high purity chlorine and caustic soda. ${ }^{4-11}$ However, excessive consumption of mercury can lead to irreversible damage to the environment and human body. ${ }^{12-15}$ As a toxic metal, mercury and its compound could cause vital organ dysfunction such as DNA damage, ${ }^{\mathbf{1 6}}$ mitosis impairment, ${ }^{17}$ and nervous system defects. ${ }^{18}$ The emission of mercury ions has been increasing due to the full speed development of the mercury industry. ${ }^{\mathbf{1 9 , 2 0}}$ Mercury ions enter the body through the food chain and accumulate gradually, which directly affects the safety of human life. To date, many sensors have been reported for the detection of $\mathrm{Hg}^{2+}$. However, some sensors are made by complex synthesis processes and expensive raw materials or are difficult to synthesize, ${ }^{21-24}$ and thus their practical applications are limited in certain aspects. Due to their rapid testing, strong practicality and easy operation, colorimetric and fluorescent sensors are the best choice for the detection of mercury(II) ions in physiological and environmental samples. ${ }^{25-29}$

Key Laboratory of Eco-Environment-Related Polymer Materials, Ministry of Education of China, Key Laboratory of Polymer Materials of Gansu Province, College of Chemistry and Chemical Engineering, Northwest Normal University, Lanzhou, Gansu, 730070, P. R. China. E-mail: weitaibao@126.com; zhangnwnu@126.com

$\dagger$ Electronic supplementary information (ESI) available: Experimental details, synthesis of M2, NMR spectra, and other materials. See DOI: 10.1039/c7ra07992c
Among the reported sensors, phenazine and its derivatives have been widely employed in the design of fluorescent sensors due to their stable optical properties, easy synthesis, cheap raw materials and large conjugate systems. ${ }^{30-32}$ They act as an important skeleton in fluorescence sensors used to identify amino acids, citrate and other ions..$^{33-35}$

According to these superior properties and our goals, ${ }^{36}$ we designed and synthesized a phenazine derivative Z-3 (Scheme 1), which could rapidly select $\mathrm{Hg}^{2+}$ in aqueous solutions. Based on its deprotonation mechanism, the fluorescent sensor could detect $\mathrm{Hg}^{2+}$ with blue fluorescence in a wide $\mathrm{pH}$ range (from 2-8). It also exhibits high selectivity $\left(2.14 \times 10^{-9} \mathrm{M}\right)$ and other common metal ions have nearly no influence on its sensing behavior. Moreover, its naked eye minimum detection limits are $10^{-5}$ and $10^{-4}$ for solution and test strips, respectively, which greatly improve the practicality of this sensor. Moreover, the test strips also can act as a reliable means for the detection of $\mathrm{Hg}^{2+}$ in real-time.

Fluorescence spectra were measured with different metal ions in DMSO $/ \mathrm{H}_{2} \mathrm{O}(\mathrm{v} / \mathrm{v}, 3: 2$, buffered with HEPES, $\mathrm{pH}=7.20)$. As shown in Fig. 1a, the addition of $\mathrm{Hg}^{2+}$ induced a distinct
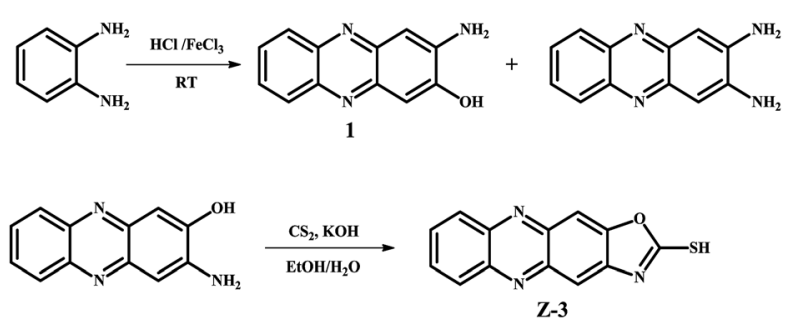

Scheme 1 Synthesis of compound Z-3. 
(a)

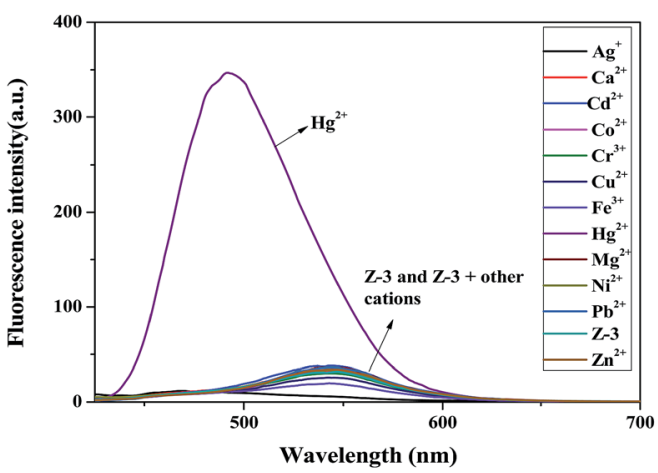

(b)

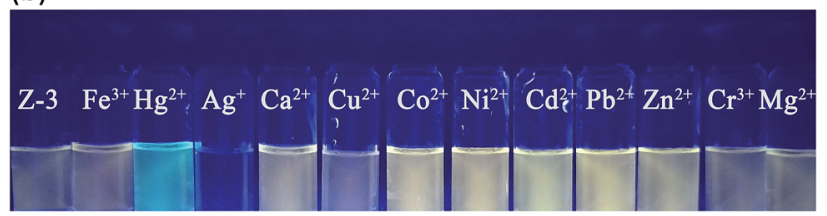

Fig. 1 (a) Fluorescence spectra $\left(\lambda_{\text {ex }}=400 \mathrm{~nm}\right)$ of Z-3 $(2 \times 10-5 \mathrm{M})$ with different metal ions: $\mathrm{Fe}^{3+}, \mathrm{Hg}^{2+}, \mathrm{Ag}^{+}, \mathrm{Ca}^{2+}, \mathrm{Cu}^{2+}, \mathrm{Co}^{2+}, \mathrm{Ni}^{2+}, \mathrm{Cd}^{2+}$, $\mathrm{Pb}^{2+}, \mathrm{Zn}^{2+}, \mathrm{Cr}^{3+}$ and $\mathrm{Mg}^{2+}$ (10 equiv., respectively) in $\mathrm{DMSO} / \mathrm{H}_{2} \mathrm{O}(\mathrm{v} / \mathrm{v}$, 3 : 2; buffered with HEPES, $\mathrm{pH}=7.20$ ). (b) Visual fluorescence emission of the Z-3 sensor upon the addition of different metal ions.

fluorescence enhancement with an obvious blue-shift (from 544 to $496 \mathrm{~nm}$ ). Moreover, the fluorescence color of the solutions changed from yellow to blue under illumination with a $365 \mathrm{~nm}$ UV lamp (Fig. 1b). We speculated that the sensor complexed with $\mathrm{Hg}^{2+}$, which resulted in the fluorescence colour change. All these facts indicate that the sensor could be used for the selective identification of $\mathrm{Hg}^{2+}$ among other cations.

The most important aspect of selective recognition is that the target analyte is detected over other possible interfering metal ions, and thus a competition experiment was carried out. In Fig. $2 \mathrm{a}$ and $\mathrm{b}$, in the presence of other metal ions, such as $\mathrm{Fe}^{3+}, \mathrm{Ag}^{+}, \mathrm{Ca}^{2+}, \mathrm{Cu}^{2+}, \mathrm{Co}^{2+}, \mathrm{Ni}^{2+}, \mathrm{Cd}^{2+}, \mathrm{Pb}^{2+}, \mathrm{Zn}^{2+}, \mathrm{Cr}^{3+}$ and $\mathrm{Mg}^{2+}$, there was no evident fluorescence emission peak shift and color change. Therefore, it is clear that the interference of other ions is negligible during the detection of $\mathrm{Hg}^{2+}$. These results further suggest that Z-3 has a strong ability to complex with $\mathrm{Hg}^{2+}$ over other metal ions and could be used as a sensor for $\mathrm{Hg}^{2+}$ over a wide range of cations.

We also performed a fluorescence titration to verify the recognition behavior sensitivity (Fig. 3). In the fluorescence spectrum, upon the addition of $\mathrm{Hg}^{2+}$ to $\mathbf{Z}-3$, the emission peak gradually blue shifted from $544 \mathrm{~nm}$ to $496 \mathrm{~nm}$ with a fluorescence color change from yellow to blue. The detection of $\mathbf{Z}-\mathbf{3}$ for $\mathrm{Hg}^{2+}$ calculated on the basis of $3 \sigma / m$ for the fluorescence spectra (Fig. S5 $\dagger$ ) is $2.14 \times 10^{-9} \mathrm{M},{ }^{37}$ which is lower than the EPA guideline of $10 \mathrm{nM}^{38}$ This result also shows that Z-3 has higher sensitivity for $\mathrm{Hg}^{2+}$ compared with other reported $\mathrm{Hg}^{2+}$ sensors (Table 1).

In order to improve the actual operating performance of the detection behavior, we studied the $\mathrm{pH}$ scope of $\mathbf{Z}-3+\mathrm{Hg}^{2+}$ and fabricated comparison test strips. As shown in Fig. 4, Z-3 with $\mathrm{Hg}^{2+}$ exhibits strong fluorescence intensity in the $\mathrm{pH}$ range of 2-
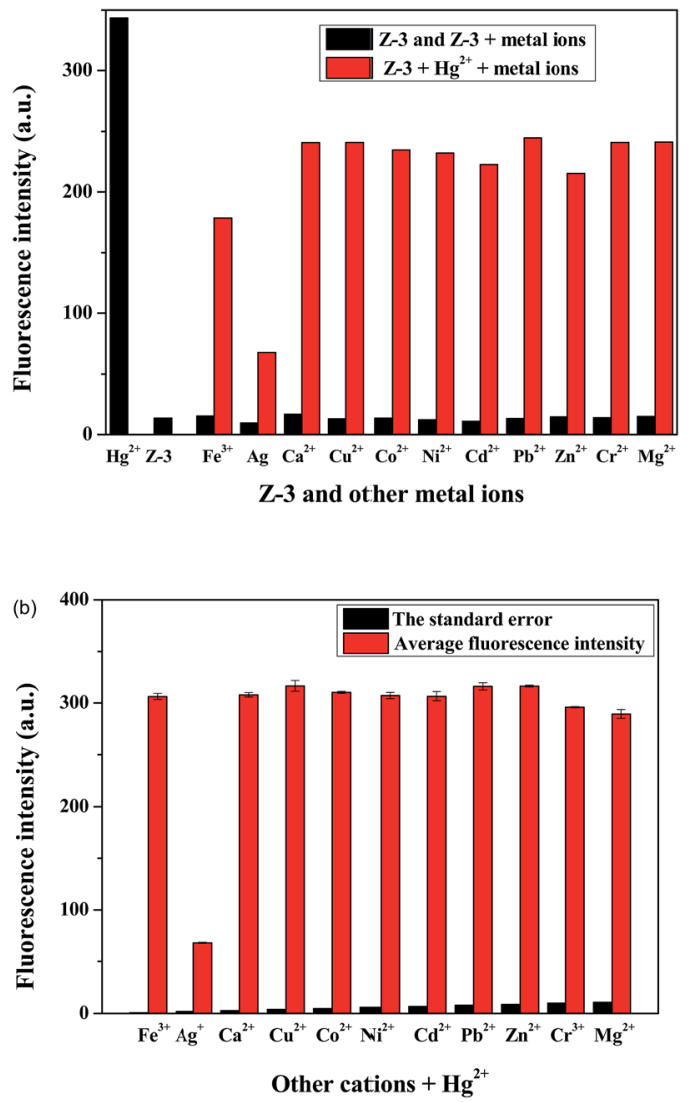

Fig. 2 (a) Fluorescence spectra of $Z-3$ and $Z-3+\mathrm{Hg}^{2+}$ in the presence of 10 equiv. various metal ions in $\mathrm{DMSO} / \mathrm{H}_{2} \mathrm{O}(\mathrm{v} / \mathrm{v}, 3: 2$; buffered with HEPES, $\mathrm{pH}=7.20$ ) solutions; (b) error bar of $\mathrm{Z}-3+\mathrm{Hg}^{2+}$ in the presence of various cations.

8, while the fluorescence intensity increases obviously at $\mathrm{pH}>8$, which may result from the fact that too high $\mathrm{pH}$ will result in a reaction between $\mathrm{Hg}^{2+}$ and -OH to form the corresponding metal hydroxides. This fact indicates that the sensor could be used in a wide $\mathrm{pH}$ range from 2 to 8 for the detection of $\mathrm{Hg}^{2+}$.

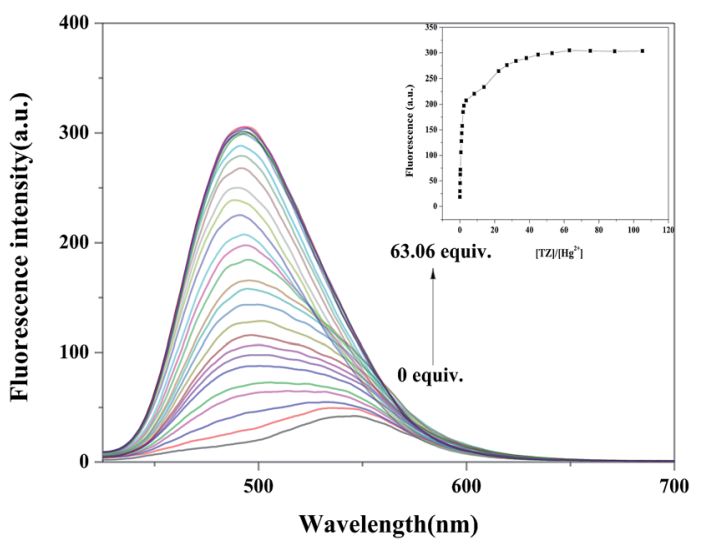

Fig. 3 Fluorescence spectra of Z-3 with different concentrations of $\mathrm{Hg}^{2+}$ in DMSO/ $\mathrm{H}_{2} \mathrm{O}(\mathrm{v} / \mathrm{v}, 3: 2$; buffered with $\mathrm{HEPES}, \mathrm{pH}=7.20)$ solutions. Insert: plot of fluorescence intensity $v s$. concentration of $\mathrm{Hg}^{2+}$ in the range of 0 to 63.06 equiv. ( $\lambda_{\text {ex }}=400 \mathrm{~nm}$ ). 
Table 1 A comparison of the detection limits for $\mathrm{Hg}^{2+}$

\begin{tabular}{llll}
\hline Method & Analyte & Solvent & Detection limit \\
\hline Ref. 39 & $\mathrm{Hg}^{2+}$ & 1-Propanol-cyclohexane & $1.7 \times 10^{-8} \mathrm{M}$ \\
Ref. 40 & $\mathrm{Hg}^{2+}$ & MeOH- ${ }_{2} \mathrm{O}$ & $2.1 \times 10^{-7} \mathrm{M}$ \\
Ref. 41 & $\mathrm{Hg}^{2+}$ & THF-HEPES & $8 \times 10^{-8} \mathrm{M}$ \\
Ref. 42 & $\mathrm{Hg}^{2+}$ & $\mathrm{CH}_{3} \mathrm{CN}-\mathrm{H}_{2} \mathrm{O}$ & $9 \times 10^{-8} \mathrm{M}$ \\
Our work & $\mathrm{Hg}^{2+}$ & DMSO-HEPES & $2.14 \times 10^{-8} \mathrm{M}$
\end{tabular}

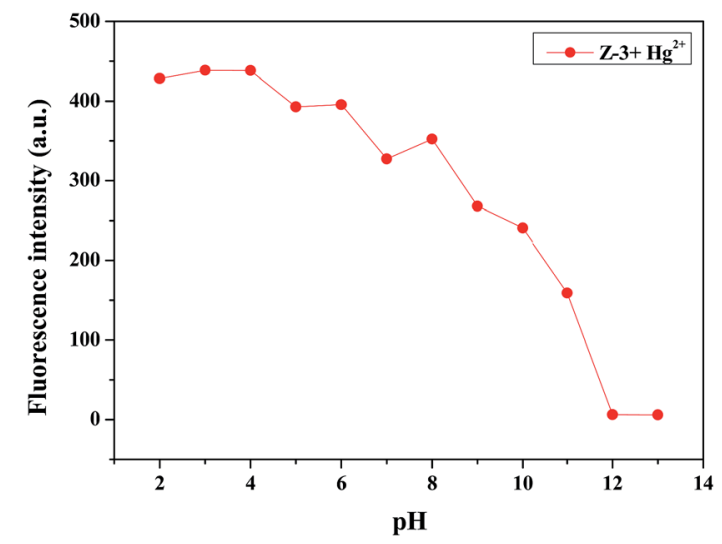

Fig. 4 Fluorescence intensity $\left(\lambda_{\mathrm{ex}}=400 \mathrm{~nm}\right.$ and $\lambda_{\mathrm{em}}=496 \mathrm{~nm}$ ) of the $\mathrm{Z}-3+\mathrm{Hg}^{2+}$ complex at various $\mathrm{pH}$ values in $\mathrm{DMSO} / \mathrm{H}_{2} \mathrm{O}(\mathrm{v} / \mathrm{v}, 3: 2$; buffered with HEPES, $\mathrm{pH}=7.20$ ) solution.

Test strips were prepared by immersing filter paper into a DMSO solution of Z-3 $\left(2 \times 10^{-4} \mathrm{M}\right)$ and then drying them in air. The test strips containing $\mathbf{Z}-3$ were utilized to sense $\mathrm{Hg}^{2+}$. As shown in Fig. 5, with a decrease in the $\mathrm{Hg}^{2+}$ concentration, the test paper fluorescence color gradually becomes yellow. The minimum identification limit of the test strips is $10^{-4} \mathrm{M}$. Moreover, the test strips could act as a convenient method for the detection of $\mathrm{Hg}^{2+}$ in an aqueous solution. We also conducted the experiments with the minimum detection limit with respect to naked eyes. As shown in Fig. 6, when the concentration of $\mathrm{Hg}^{2+}$ is $10^{-6} \mathrm{M}$, the fluorescence color of the solution is consistent with the sensor (Z-3). We thought that the lowest detection limit of $\mathrm{Hg}^{2+}$ was $10^{-5} \mathrm{M}$.

In order to study the combination of mercury ions(II) with Z3, we first studied the isomerization of Z-3. As shown in Fig. $\mathrm{S} 1, \dagger$ the peak at $14.41 \mathrm{ppm}$ is ascribed to the $-\mathrm{NH}$ proton in the ${ }^{1} \mathrm{H}$ NMR spectrum. Moreover, we also observed a peak at $2675 \mathrm{~cm}^{-1}$ in the IR spectrum (Fig. S2 $\dagger$ ), which is the characteristic peak of

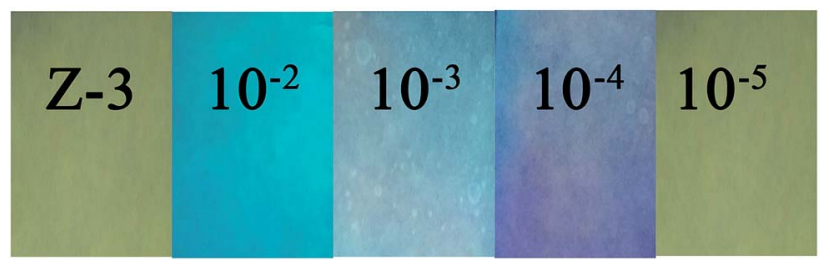

Fig. 5 Photographs of test strips (the concentration of $\mathrm{Hg}^{2+}$ is $0 \mathrm{M}$, $10^{-1} \mathrm{M}, 10^{-2} \mathrm{M}, 10^{-3} \mathrm{M}, 10^{-4} \mathrm{M}, 10^{-5} \mathrm{M}$, both under an UV lamp at $365 \mathrm{~nm}$ )

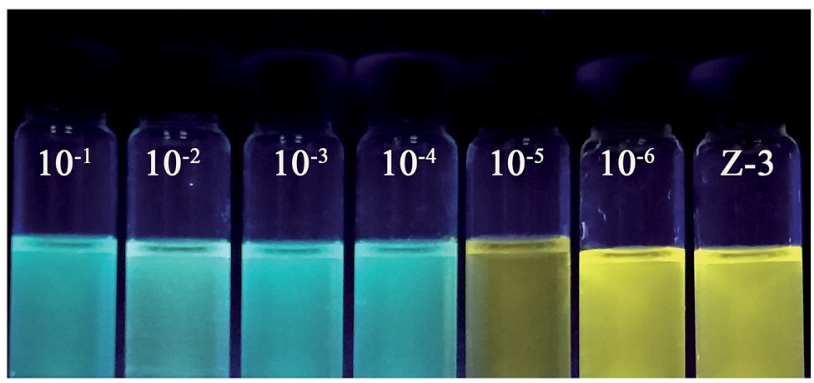

Fig. 6 Naked-eyes detection limit under UV lamp at $365 \mathrm{~nm}$.from left to right, the concentration of $\mathrm{Hg}^{2+}$ is $10^{-1} \mathrm{M}, 10^{-2} \mathrm{M}, 10^{-3} \mathrm{M}, 10^{-4} \mathrm{M}$, $10^{-5} \mathrm{M}, 10^{-6}$ and $0 \mathrm{M}$.

-SH. Based on these facts, we believe that Z-3 has two tautomers of thioketone $(=\mathrm{S})$ and thiols $(-\mathrm{SH})$, and the structure of thione $(=\mathrm{S})$ is the main form in solution. From the ${ }^{1} \mathrm{H}$ NMR titration (Fig. 7), the peak at $14.41 \mathrm{ppm}$ disappeared with the addition of $\mathrm{Hg}^{2+}$, which suggests that the complexation occurred after the -NH proton was fully deprotonated. Amazingly, the solution precipitated solid on the addition of 0.2 equivalents of mercury ions. We speculate that it may be from the perchlorate, and its molecular formula may be $[\mathrm{Z}-3+\mathrm{Hg}]^{+} \mathrm{ClO}_{4}{ }^{-}$. In addition, we also carried out an IR experiment on the solid of $\mathbf{Z - 3}$ and $\mathbf{Z - 3}+\mathrm{Hg}^{2+}$. As shown in Fig. $\mathrm{S} 3, \dagger$ the peak at $2675 \mathrm{~cm}^{-1}$, which was recognized as the characteristic peak of $-\mathrm{SH}$, disappeared upon the addition of $\mathrm{Hg}^{2+}$. All these results indicate that the mercury ions coordinated with the sulfur atom and nitrogen atom on the oxazole ring after the protonation of the sensor.

Moreover, in order to clarify the stoichiometric relationship between $\mathrm{Hg}^{2+}$ and $\mathbf{Z}-3$, the Job plot was obtained. As shown in Fig. 8, the fluorescence intensity at $496 \mathrm{~nm}$ was plotted against molar fraction of Z-3 sensor. The maximum emission intensity was reached when the molar fraction was 0.4. This result manifests a $1: 1$ ratio for the $\mathbf{Z}-3+\mathrm{Hg}^{2+}$ complex.

Based on all these facts, we propose a reasonable mechanism for the detection of $\mathrm{Hg}^{2+}$ by the sensor in an aqueous solution (Fig. 9). We hypothesize that the thiocarbonyl and secondary amine nitrogen of the oxazole motif coordinate with $\mathrm{Hg}^{2+}$, and then the complex and perchloric acid form a salt and precipitate.

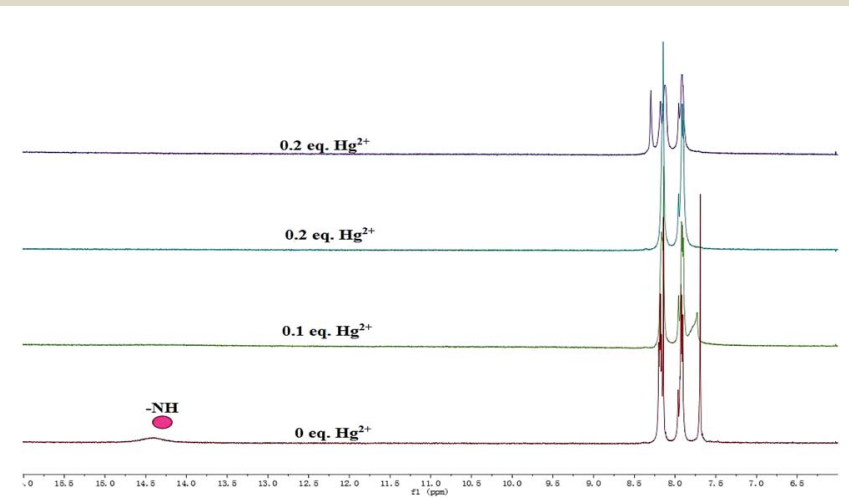

Fig. 7 Partial $1 \mathrm{H}$ NMR spectra of $\mathrm{Z}-3$ in DMSO- $\mathrm{d}_{6}$ with different concentrations of $\mathrm{Hg}^{2+}$. 


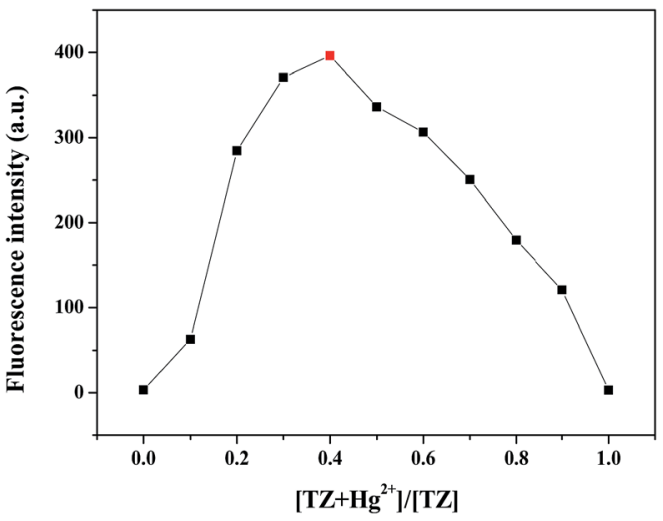

Fig. 8 Job plot examining the relationship between $\mathrm{Z}-3$ and $\mathrm{Hg}^{2+}$

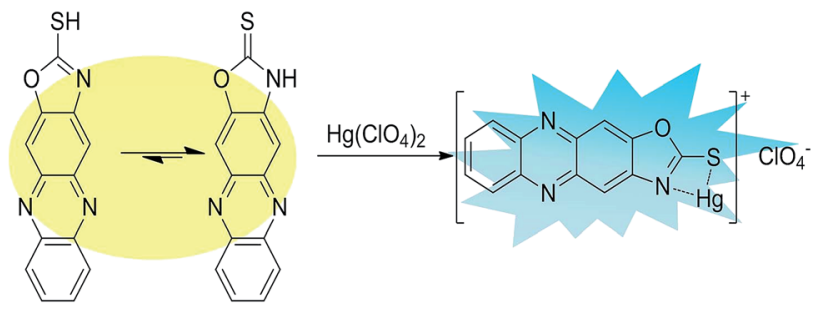

Fig. 9 Possible binding mode of $\mathrm{Z}-3$ with $\mathrm{Hg}^{2+}$

In conclusion, we obtained a fluorescent sensor Z-3 via a simple method for the detection of $\mathrm{Hg}^{2+}$, which displays high selectivity and sensitivity in the recognition process. The sensor exhibits an obvious fluorescence colour change from yellow to blue, and its detection behaviour operates in a wide $\mathrm{pH}$ range. Moreover, its test strips and naked-eyes minimum detection limit greatly improve the practicality of $\mathbf{Z}-\mathbf{3}$. Hence, this study also implies that phenazine and its derivatives are potential candidates for the detection of ions.

\section{Conflicts of interest}

There are no conflicts to declare.

\section{Acknowledgements}

This study was supported by the National Natural Science Foundation of China (NSFC) (No. 21662031; 21661028; 21574104; 21262032), the Natural Science Foundation of Gansu Province (1506RJZA273) and the Program for Changjiang Scholars and Innovative Research Team in University of Ministry of Education of China (IRT 15R56).

\section{Notes and references}

1 C. Caltagirone and P. A. Gale, Chem. Soc. Rev., 2009, 38, 520. 2 R. Zare-Dorabei, R. Rahimi, A. Koohi and S. Zargari, RSC Adv., 2015, 5, 93310.
3 D. G. Streets, M. K. Devane, Z. Lu, T. C. Bond, E. M. Sunderland and D. J. Jacob, Environ. Sci. Technol., 2011, 45, 10485.

4 L. Wang, J. Jin, L. Zhao, H. Shen, C. Shen and P. Zhang, Carbohydrate Research, 2016, 433, 41.

5 K. P. Carter, A. M. Young and A. E. Palmer, Chem. Rev., 2014, 114, 4564.

6 J. Kuchlyan, S. Basak, D. Dutta, A. K. Das and D. Ma, Chem. Phys. Lett., 2017, 673, 84.

7 T. Yu, T. T. Zhang, W. Zhao, J. J. Xu and H. Y. Chen, Talanta, 2017, 165, 570.

8 N. Busschaert, C. Caltagirone, W. V. Rossom and P. A. Gale, Chem. Rev., 2015, 115, 8038.

9 C. T. Driscoll, R. P. Mason, H. M. Chan, D. J. Jacob and N. Pirrone, Environ. Sci. Technol., 2013, 47, 4967.

10 H. H. Wang, L. Xue, C. L. Yu, Y. Y. Qian and H. Jiang, Dyes Pigm., 2011, 91, 350.

11 (a) L. Campbell, D. G. Dixon and R. E. Hecky, J. Toxicol. Environ. Health, Part B, 2003, 6, 325; (b) Q. Ye, F. Yan, Y. Luo, Y. Wang, X. Zhou and L. Chen, Spectrochim. Acta, Part A, 2017, 173, 854; (c) C. Jiang, Z. Guan, S. Y. Rachel Lim, L. Polavarapu and Q. H. Xu, Nanoscale, 2011, 3, 3316; (d) Y. Chen, L. Wu, Y. Chen, N. Bi, X. Zheng, H. Qi and M. Qin, Microchim. Acta, 2012, 177, 341.

12 (a) Y. Li, H. Huang, Y. Li, X. Su, Y. Li, H. Huang, Y. Li and X. Su, Sens. Actuators, B, 2013, 188, 772; (b) W. Ren, C. Zhu and E. Wang, Nanoscale, 2012, 4, 5902; (c) E. O. Ganbold, J. H. Park, K. S. Ock and S. W. Joo, Bull. Korean Chem. Soc., 2011, 32, 519.

13 C. Chen, R. Wang, L. Guo, N. Fu, H. Dong and Y. Yuan, Org. Lett., 2011, 13, 1162.

14 H. H. Harris, I. J. Pickering and G. N. George, Science, 2003, 301.

15 P. B. Tchounwou, W. K. Ayensu, N. Ninashvili and D. Sutton, Environ. Toxicol., 2003, 18, 149.

16 C. Wu, J. Wang, J. Shen, C. Bi and H. Zhou, Sens. Actuators, B, 2017, 243, 678.

17 I. Samb, J. Bell, P. Y. Toullec, V. Michelet and I. Leray, Org. Lett., 2011, 13, 1182.

18 Y. Ding, W. Zhu, Y. Xu and X. Qian, Sens. Actuators, B, 2015, 220, 762.

19 X. Ma, J. Wang, Q. L. Shan, Z. W. Tan, G. H. Wei, D. B. Wei and Y. G. A. Du, Org. Lett., 2012, 14, 820.

20 (a) Z. S. Qian, X. Y. Shan, L. J. Chai, J. J. Ma, J. R. Chen and H. Feng, ACS Appl. Mater. Interfaces, 2014, 6, 6797; (b) P. F. Wei, D. B. Li, B. B. Shi, Q. Wang and F. Huang, Chem. Commun., 2015, 51, 15169; (c) C. H. Yao, Y. H. Cao, Q. Wang, Y. Pan, J. L. Jiang and L. Y. Wang, Chem. Commun., 2016, 52, 8715; (d) C. Jin, M. Zhang, L. Wu, Y. F. Guan, Y. Pan, J. L. Jiang, C. Lin and L. Y. Wang, Chem. Commun., 2013, 49, 2015.

21 X. F. Wu, Q. J. Ma, X. J. Wei, Y. M. Hou and X. Zhu, Sens. Actuators, B, 2013, 183, 565.

22 Z. Chen, T. Lou, Q. Wu, K. Li, L. Tan and J. Sun, Sens. Actuators, B, 2015, 221, 36. 
23 P. Jarujamrus, M. Amatatongchai, A. Thima, T. Khongrangdee and C. Mongkontong, Spectrochim. Acta, Part A, 2015, 142, 86.

24 M. Taki, K. Akaoka, S. Iyoshi and Y. Yamamoto, Inorg. Chem., 2012, 51, 13075.

25 (a) L. Y. Wang, L. H. Zhu and D. Cao, New J. Chem., 2015, 39, 7211; (b) X. Y. Hu, X. Wu, Q. Duan, T. Xiao, C. Lin and L. Wang, Org. Lett., 2012, 14, 4826; (c) M. Xue, Y. Yang, X. Chi, Z. Zhang and F. Huang, Acc. Chem. Res., 2012, 45, 1294; (d) L. Y. Wang, X. G. Chen and D. Cao, RSC Adv., 2016, 6, 96676.

26 (a) W. Ren, Y. Zhang, H. G. Chen, H. Z. F. Gao, N. B. Li and H. Q. Luo, Anal. Chem., 2016, 88, 1385; (b) K. Johari, N. Saman, S. T. Song, S. C. Cheu, H. Kong and H. Mat, Chemosphere, 2016, 156, 56; (c) S. Sun, X. Y. Hu, D. Chen, J. Shi, Y. Dong, C. Lin, Y. Pan and L. Wang, Polym. Chem., 2013, 4, 2224; (d) Y. Chen, M. He, B. Li, L. Wang, H. Meier and D. Cao, RSC Adv., 2013, 3, 21405.

27 E. M. Nolan and S. J. Lippard, Chem. Rev., 2008, 108, 3443. 28 D. T. Quang and J. S. Kim, Chem. Rev., 2010, 110, 6280.

29 C. Zhu, L. Li, F. Fang, J. Chen and Y. Wu, Chem. Lett., 2005, 34, 898.

30 (a) D. C. Lee, B. Cao, K. Jang and P. M. Forster, J. Mater. Chem., 2010, 20, 867; (b) V. S. S. Mosali, G. A. Bowmaker, M. Gerard, P. A. Kilmartin, J. T. Sejdicb and Z. D. Zujovicb, Polym. Int., 2015, 64, 1135; (c) S. Biradar, Y. Shigemitsu, Y. Kubota, K. Funabiki, H. Satoc and M. Matsui, RSC Adv., 2014, 4, 59387; (d) J. F. Zhao, Y. Liu, J. B. Soh, Y. X. Li, R. Ganguly, K. Q. Ye, F. Huo, L. Huang, A. I. Y. Tok, J. S. C. Loo and Q. Zhang, Tetrahedron Lett., 2012, 53, 6044; (e) J. Zhao, G. Li, C. Wang, W. Chen, S. C. J. Loo and Q. Zhang, RSC Adv., 2013, 3, 9653.

31 C. J. Tonzola, M. M. Alam, W. Kaminsky and S. A. Jenekhe, J. Am. Chem. Soc., 2003, 125, 13548.
32 (a) F. J. Huo, J. Su, Y. Q. Sun, C. X. Yin, J and B. Chao, Chem. Lett., 2010, 39, 738; (b) Y. A. Son, Y. M. Park, S. Y. Park, C. J. Shin and S. H. Kim, Dyes Pigm., 2007, 73, 76; (c) J. Xu, S. B. Sun, Q. Li, Y. Yue, Y. D. Li and S. J. Shao, Anal. Chim. Acta, 2014, 849, 36; (d) F. J. Huo, C. X. Yin, Y. T. Yang, J. Su, J. B. Chao and D. S. Liu, Anal. Chem., 2012, 84, 2219; (e) S. Erdemir and O. Kocyigit, Sens. Actuators, B, 2015, 221, 900; (f) C. J. Gao, X. J. Jin, X. H. Yan, P. An, Y. Zhang, L. L. Liu, H. Tian, W. S. Liu, X. J. Yao and Y. Tang, Sens. Actuators, B, 2013, 176, 775.

33 X. Zhang, Y. Yan, Y. Hang, J. Wang, J. Hua and H. Tian, Chem. Commun., 2017, 53, 5760.

34 Y. Gao, G. Huang, Z. Ou, Z. Wang, B. Ju, Y. Li, X. Wang and S. Yin, New J. Chem., 2015, 39, 8948.

35 (a) P. Y. Gu, Z. Wang and Q. Zhang, J. Mater. Chem., 2016, 4, 7060; (b) J. Li, J. Gao, W. W. Xiong, P. Z. Li, H. Zhang, Y. Zhao and Q. Zhang, Chem.-Asian J., 2014, 9, 121; (c) J. F. Zhao, Y. Liu, J. B. Soh, Y. X. Li, R. Ganguly, K. Q. Ye, F. Huo, L. Huang, A. I. Y. Tok, J. S. C. Loo and Q. Zhang, Tetrahedron Lett., 2012, 53, 6044.

36 (a) W. T. Li, G. Y. Wu, W. J. Qu, Q. Li, J. C. Lou, Q. Lin, H. Yao, Y. M. Zhang and T. B. Wei, Sens. Actuators, B, 2017, 239, 671;

(b) H. L. Zhang, T. B. Wei, W. T. Li, W. J. Qu, Y. L. Leng, J. H. Zhang, Q. Lin, Y. M. Zhang and H. Yao, Spectrochim. Acta, Part A, 2017, 175, 117.

37 Analytical Methods Committee, Analyst 1987, 112, 199.

38 H. F. Wang and S. P. Wu, Tetrahedron, 2013, 69, 1965.

39 N. A. Bumagina, E. V. Antina and D. I. Sozonov, J. Lumin., 2017, 183, 315.

40 Y. Lei, H. Li, X. Huang, J. Chen, M. Liu, W. Gao, J. Ding, D. Lin and H. Wu, Tetrahedron, 2015, 71, 3453.

41 M. Kaur, M. J. Cho and D. H. Choi, Dyes Pigm., 2016, 125, 1. 42 I. Samb, J. Bell, P. Y. Toullec, V. Michelet and I. Leray, Org. Lett., 2011, 13, 1182. 